\title{
ABC Spotlight on effect-directed analysis-dose instead of concentration
}

\author{
Günter Gauglitz
}

Received: 12 February 2015 / Accepted: 12 February 2015 / Published online: 8 March 2015

(C) Springer-Verlag Berlin Heidelberg 2015

In analysis, normally the concentration of samples is determined, components are identified from their spectra, or the structure of components is elucidated. However, in the 1990s the first approaches combining chemical analysis with bio-testing were published [1]. This approach introduced the concept of measuring the dose rather than the concentration to the field of analysis, by extrapolating from the principles applied in dosimeters used for people in contact with X-rays and from drug design in pharmacokinetics and/or pharmacodynamics, where the dose is relevant. In 2003, ABC published an extensive review on effect-directed analysis (EDA) as a promising tool for identifying organic toxicants in complex mixtures for the first time [2].

Effect-directed analysis, sometimes also called effect-based analysis or effect-oriented analysis, was first used to apply this combination of bio-testing and physicochemical fractionation by using organic-solvent extracts for HPLC or massspectrometry measurements. It was first used to determine the amount of contamination by complex mixtures of toxicants that were believed to be potentially hazardous to ecosystems and human health. As a result, a special issue of $A B C$ on effect-oriented environmental analysis [3] and a large number of papers have been published; these even include screening mutagenic fractions using combinations of chromatography and mass spectrometry [4]. The integrated approach was also used in a field study at the river Elbe to measure the effect of polyaromatic compounds to understand the detected mutagenics effects [4]. An interesting aspect that arose from this

G. Gauglitz $(\bowtie)$

Institute of Physical and Theoretical Chemistry, Eberhard Karls Universität, Auf der Morgenstelle 18, 72076 Tübingen, Germany

e-mail: abc.gg@ipc.uni-tuebingen.de research was the need to understand the effects on human health of growth-promoter residues in foods. Another approach is effect-based proteomic detection [5]. Non-targetanalysis measurements of metabolites and abiotictransformation products of original pollutants in water and the consequences for human health led to another special issue of $\mathrm{ABC}$ that dealt with analytical challenges in environmental and geosciences [6].

The ongoing development of biosensors enabled a more accurate and easier measurement of interactions between analytes and recognition elements. Recently, an extensive review was published that revealed the different possibilities of measuring these interaction processes between molecules and proteins without labels, and compared widely used standard analytical methods, namely HPLC-MS, MNR calorimetry, and X-ray diffraction, in relation to biosensors and cell lines, animal models, and even in-silico approaches [7]. Biosensors based on receptors even offered the interesting possibility of using a new type of recognition element for effect-based analysis. This new approach uses receptor molecules present in human beings that measure the dose and that are the main interest of effect-oriented analysis. They react to a class of compounds, meaning that known and unknown effective analytes are measured in total on the basis of their effects on the human being and can, as in the case of nuclear receptors, be activated by these "ligands", and they also have a crucial function in cell signaling [8]. In environmental and food analyses the endocrine-disrupting compounds, in particular, are believed to have drastic and unknown effects on human health. For this reason, estrogen receptor $\alpha(\mathrm{ER} \alpha)$ is the focus of much research because it reacts in different ways to agonists and antagonists. These effects can be measured by using specific biosensors, as revealed in Ref. [9] (Fig. 1). 


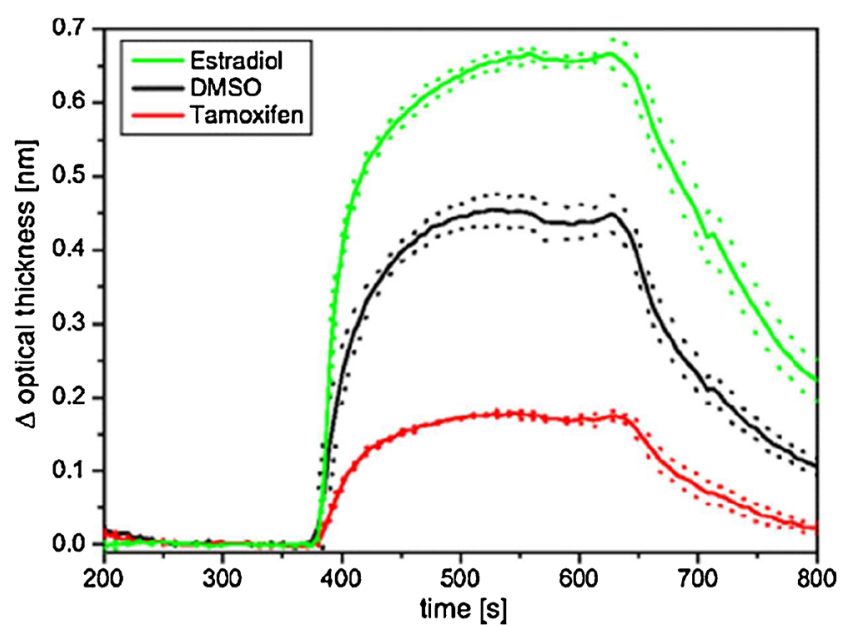

Fig. 1 Binding curves of ER $\alpha$-LBD. Different responses of the biosensor to different ligand treatments with $\mathrm{ER} \alpha-\mathrm{LBD}$. Each curve contains the information of three consecutive measurements on the same transducer, with the corresponding standard deviation. The samples contained $0.1 \mathrm{mg} \mathrm{mL}^{-1} \mathrm{ER} \alpha$-LBD incubated with $10 \mu \mathrm{g} \mathrm{mL}^{-1} \beta$-estradiol (green curve), with $10 \mu \mathrm{g} \mathrm{mL}^{-1}$ tamoxifen (red curve), or with $1 \% \mathrm{DMSO}$ (black curve) (from Ref. 9)
$\mathrm{ER} \alpha$ as a bioreporter is also applied on paper strips to obtain response curves, for example for bisphenol A [10]. Sample preparation, fractionation strategies including polarity-based fractionation, and ER-binding-affinity-based fractionation are used. They enable chemical identification of unknown compounds in the fractions and lead to results expressed as biological toxic equivalents [11]. The fractionation procedure and combination with an in-vitro bioassay and chemical analysis are shown in Fig. 2.

The importance of measuring dose instead of concentration is emphasized by the fact that the Bundesinstitut für Risikobewertung in Berlin has set up an "Effect-Based Analytics and Toxicokinetics" unit, which is in close contact with the Department of Food Safety. Furthermore, for many years the Helmholtz-Zentrum für Umweltforschung (UFZ) in Leipzig has had a department of "Wirkungsorientierte Analytik" in the field of toxicology to take into account this growing interest in modern analysis. In connection with the Excellence Initiative of the DFG, the University of Tübingen created a new professorship for effect-based analysis. Beyond these
Fig. 2 Overall fractionation strategy used for the isolation and identification of PXR and ER ligands in sediment extract. (FT flow-through; washing fractions, L1-L3; elution fractions, E1-E4) (From Ref. 11)

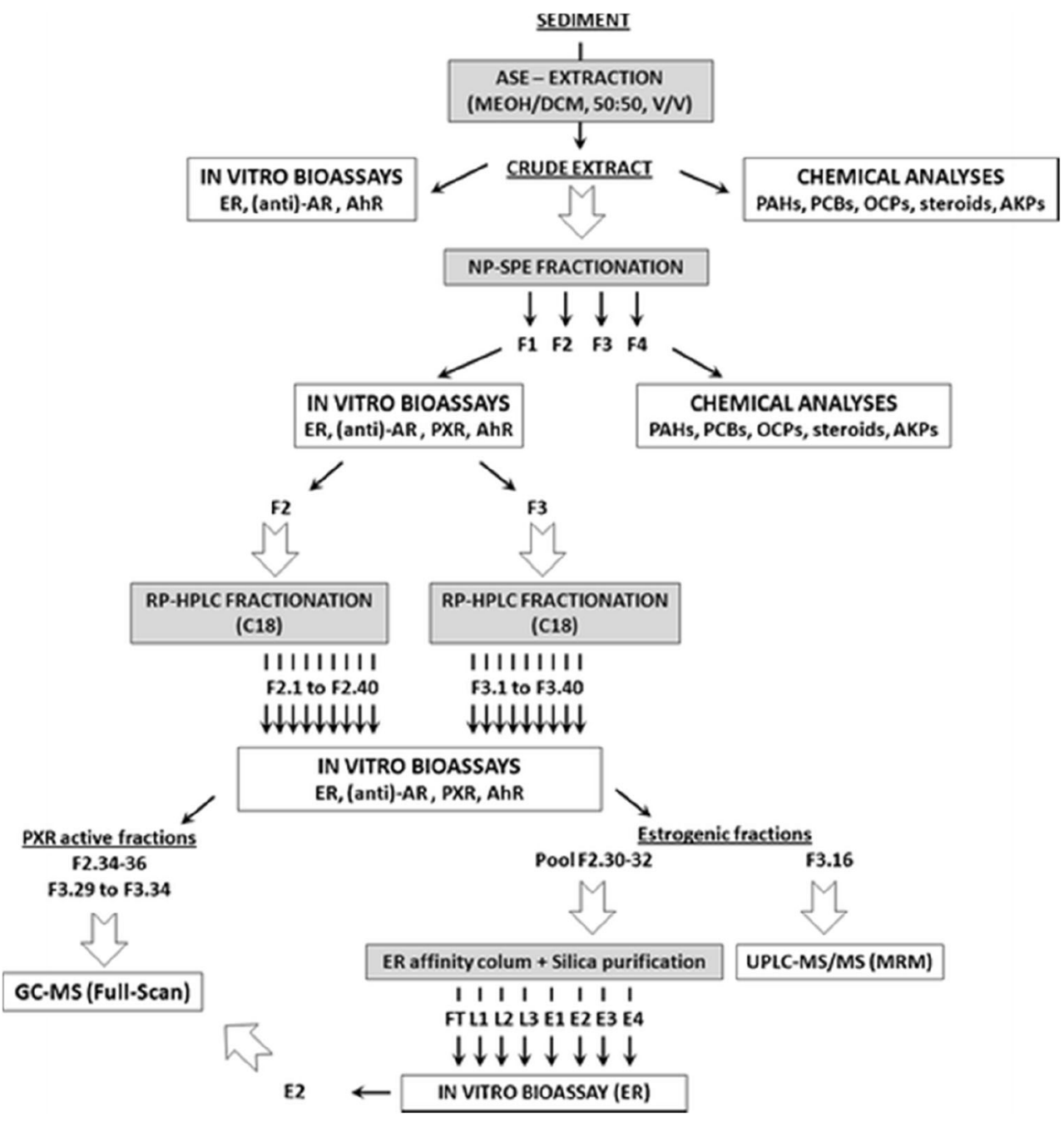


activities in environmental and food analysis, this new development of measuring dose instead of concentration will go far beyond these approaches; certainly in the field of fermentation. In fermentation, during the biotechnological production of drugs, some of the metabolites have similar activity and their effects are better measured by an "active center" at the recognition element than by standard concentration measurements using HPLC or mass spectrometry. In addition, the effect of agonists and antagonists on the signal chain will be of interest for systems biology and, last but not least, for the development of drugs with high effectivity and few side effects. In the past, $\mathrm{ABC}$ followed the development of effectbased analysis, and will be happy to receive publications in the future that deal with the aspects mentioned above.

\section{References}

1. Schuetzle D, Lewtas J (1986) Bioassay-directed chemical analysis in environmental research. Anal Chem 58(11):1060A-1075A

2. Brack W (2003) Effect-directed analysis: a promising tool for the identification of organic toxicants in complex mixtures? Anal Bioanal Chem 377:397-407

3. Suter MJ-F (2008) Effect-oriented environmental analysis. Anal Bioanal Chem 390:1957-1958

4. Gallampois C-M-J, Schymanski E-L, Bataineh M, Buchinger S, Krauss M, Reifferscheid G, Brack W (2013) Integrated biologicalchemical approach for the isolation and selection of polyaromatic mutagens in surface waters. Anal Bioanal Chem 405:9101-9112

5. McGrath TF, van Meeuwen J-A, Massart A-C, de Pauw E, Delahaut P, Buijs J, Bergwerff A-A, Elliott C-T, Mooney M-H (2013) Effectbased proteomic detection of growth promoter abuse. Anal Bioanal Chem 405:1171-1179

6. Zwiener C (2012) Analytical Challenges in Environmental and Geosciences. Anal Bioanal Chem 403:2469-2470

7. Fechner P, Bleher O, Ewald M, Freudenberger K, Furin D, Hilbig U, Kolarov F, Krieg K, Leidner L, Markovic G, Proll G, Pröll F, Rau S,
Riedt J, Schwarz B, Weber P, Widmaier J (2014) Size does matter! Label-free detection of small molecule-protein interaction. Anal Bioanal Chem 406:4033-4051

8. Fechner P, Gauglitz G, Gustafsson J-A (2010) Nuclear receptors in analytics - a fruitful joint venture or a wasteful futility? Trends Anal Chem 29:297-305

9. Fechner P, Pröll F, Carlquist M, Proll G (2009) An advanced biosensor for the prediction of estrogenic effects of endocrine-disrupting chemicals on the estrogen receptor alpha. Anal Bioanal Chem 393: $1579-1585$

10. Rajasärkkä J, Koponen J, Airaksinen R, Kiviranta H, Virta M (2014) Monitoring bisphenol A and estrogenic chemicals in thermal paper with yeast-based bioreporter assay. Anal Bioanal Chem 406: 5695-5702

11. Creusot N, Budzinski H, Balaguer P, Kinani S, Porcher J-M, AitAissa S (2013) Effect-directed analysis of endocrine-disrupting compounds in multi-contaminated sediment: identification of novel ligands of estrogen and pregnane X receptors. Anal Bioanal Chem 405:2553-2566

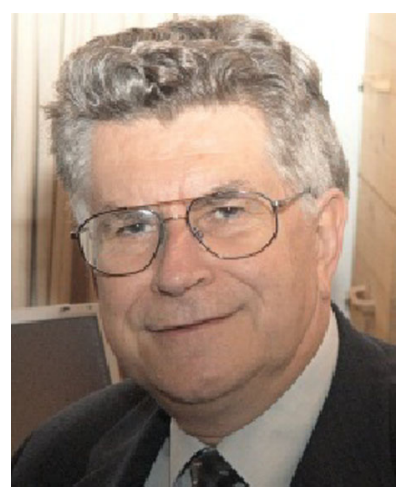

Günter Gauglitz is Senior Professor at the Eberhard Karls University of Tübingen working in analytical and physical chemistry. He was chairman of the GDCh Division of Analytical Chemistry and chaired the Europt(r)ode VIII meeting. For more than 15 years his main scientific interest has been on research and development of chemical and biochemical sensors, with special focus on the characterization of interfaces of polymers and biomembrane surfaces, spectroscopy techniques, use of spectral interferometry to monitor changes in optical thickness of thin layers, and effects of Fresnel reflectivity at interfaces. He has been an editor of Analytical and Bioanalytical Chemistry (ABC) since 2002. 